\title{
Una reflexion sobre los medios de integracion del emigrante vasco en America y Europa durante el siglo XVIII
}

ALBERTO ANGULO MORALES*

Resumo: Este texto constitui uma abordagem alternativa às análises sobre os mecanismos utilizados pelos imigrantes bascos no final da Era Moderna, tanto em suas migrações de curta distância quanto nas de longa distância. Sugiro que essas migrações eram mediadas por laços pessoais e familiares.

Abstract: This paper representes an alternative approach to the analysis of the mechanisms used by the Basque immigrants during the Late Modern Age concerning both short and long-distance migrarations. I will propose that these migration processes were arranged by personal and familiar ties.

Palavras-chave: País Basco. Migração. Laços familiares e pessoais.

Key words: Basque country. Migration. Familiar and personal ties.

El descubrimiento de nuevas fronteras, a la par que de sus respectivos mundos sociales, políticos y económicos, se manifiesta como una constante a lo largo de la evolución histórica. En este mismo proceso, indisolublemente unido a los nuevos parajes, se aglutina un amplio agregado de experiencias y posibilidades, promovidas por la oferta potencial de nuevas oportunidades para quienes dirigen sus pasos y miradas hacia los nuevos territorios. Estas migraciones, estimuladas tanto por las condiciones existentes en los lugares originales de partida como en los nuevos espacios, pueden

Doctor en Historia. Professor de Historia Moderna de la Facultad de Filologia, Geografia e Historia de la Universidad del País Basco, España. 
significarse por su encuadramiento dentro de una duplicidad de tendencias bien diferentes: las ávidas avalanchas de personas, la emigración en masa, ${ }^{1}$ o los limitados y selectivos movimientos de población que se venían produciendo cotidianamente a lo largo del antiguo régimen.

En ambos casos, el movimiento migratorio plantea un problema de especial relevancia para los historiadores, que estriba en el análisis de los medios y mecanismos que estas personas o colectivos emplean al planear y ejecutar el proceso migratorio y que, frecuentemente, se engarzarán con las líneas directrices que condicionan su posible organización y funcionamiento en el nuevo lugar de instalación como, en gran medida, lo venían efectuando en sus lugares de origen. Así, la presencia de colectivos homogéneos localizados en áreas muy precisas, ha sido profusamente analizado gracias a las indicaciones extraídas de análisis cuantitativos, obtenidos a partir de los listados especializados del personal administrativo, de las oligarquías urbanas, de entidades religiosas, del ámbito mercantil o de sociedades de pensamiento.

En estas diversas instituciones, tan diferentes como importantes para la vida social de cualquier comunidad, la presencia de personas oriundas del territorio vasco muestra, desde los albores del siglo XVIII, un peso de una gran consideración. La arribada de diversas oleadas surgidas del mar, "con las nuevas corrientes del comercio, encarnado por los burócratas de los Borbones y los nuevos comerciantes ibéricos", coinciden con la instalación de la monarquía borbónica en el trono castellano. ${ }^{2}$ La prestancia que muestran los emigrantes, a la hora de utilizar los mecanismos de integración imprescindibles, así como para avanzar por los vericuetos de la sociedad del antiguo régimen, y su favorable éxito, se convierten en uno de los hitos que fomentarán el interés de cualquier investigador por analizar los medios usados por estos colectivos - en nuestro caso nos referiremos estrictamente al caso de

\footnotetext{
Fernández de Pinedo, Emiliano. "Los movimientos migratorios vascos, en especial hacia América". In: Sánchez Albornoz, Nicolás (coord.). Españoles hacia América. La emigración en masa,1880-1930. Madrid: Alianza, 1988, p. 105-123. Gallego, José Andrés et alii. Navarra y América. Madrid: Mapfre, 1992. Como trabajos específicos véanse: Camos Argaluza, Maite. La inmigración vasca en Chile 1880-1990. Chile: Gobierno Vasco, 1991; o Alvarez Gila, Oscar. "El misionerismo y la presencia religiosa vasca en América (19311940): dificultades y emigraciones forzosas". Mundaiz (separata), $\mathrm{n}^{2} 42,1991$, p. 89-102.

2 Balmori, Diana, Stuart, F. Voss y Wortman, Miles. Las alianzas de familias y la formación del país en América Latina. México: Fondo de Cultura Económica, 1990, p. 78. Se refiere específicamente al área centroamericana aunque un proceso paralelo se viene a producir, durante todo el siglo XVIII, en los diferentes territorios americanos dominados por la Corona castellana.
} 
los oriundos de las provincias vascas - que se instalan en territorio americano durante el siglo XVIII.

El trayecto recorrido por quienes emigran tanto a espacios lejanos, en el más amplio sentido del término, ${ }^{3}$ como a otros más próximos, precisa de un compuesto de mecanismos que permita el funcionamiento exitoso del traslado. Como veremos posteriormente en el caso vasco, a pesar de su relevancia, no se generaron instrumentos específicos para el desarrollo de esta acción sino que, básicamente, se tiende al empleo de los vínculos y redes de relaciones ya existentes y que, en general, venían y seguirían siendo aplicados para una amplia multiplicidad de funciones y objetivos.

\section{Las respuestas a un espacio novedoso. Nuevos problemas y soluciones o pervivencia de mecanismos ya conocidos}

El trasvase de personas oriundas del País Vasco, durante el siglo XVIII, hacia al espacio americano, puede mostrarse como el mantenimiento de una constante perenne desde los primeros momentos del descubrimiento de estos territorios. ${ }^{4}$ De esta manera, cualquier análisis sobre los procesos emigratorios de población vasca hacia América, debe ser comprendido durante el setecientos partiendo de una situación en la que ya se encuentra la presencia, por asentamiento, de una base social vasca en numerosas y

Es decir, no sólo nos referimos a una lejanía geográfica sino también a la propia de un mundo que cuenta con unas estructuras sociales, políticas, económicas e, incluso, culturales diseñadas de manera diferente a las originales del grupo o individuo emigrante y, por encima de todo, a un mundo en el que el componente social articulado resulta ajeno y desconocido para el recién llegado.

Tras las sucesivas oleadas de emigrantes peninsulares, provenientes principalmente de áreas concretas como Extremadura o Andalucía, el siglo XVIII se convierte en la "edad de oro" de la emigración vasca hacia estos territorios, aunque también existan diferencias entre las áreas receptoras. Lohmann Villena, Guillermo. "Los Comerciantes vascos en el Virreinato Peruano". In: Escobedo, Romald, Rivera Medina, Ana María y Chapa Imaz, Alvaro (coords.). Los Vascos y América. Bilbao: Fundación Banco de Vizcaya, 1989, p. 55. Por ejemplo, su llegada primordial al área bonaerense se establece con anterioridad, a partir de mediados del siglo XVII, concretamente desde 1660 . Mariluz Urquijo, José Me. "Proyección y límites del comercio vasco en el Río de la Plata", idem, p. 107-135. El proceso migratorio, de los siglos XVI y XVII, puede advertirse, con nitidez, mediante una rápida visión de los amplios y sucesivos números del trabajo de Romera Imela, Luis y Galdós Díez, Me del Carmen. Catálogo de Pasajeros a Indias. Siglos XVI, XVII y XVIII. Sevilla: Archivo General de Indias, 1981. 
diferentes partes del espacio americano. ${ }^{5}$ Este colectivo emigrante tiende a estar, en gran manera, íntimamente vinculado con la gestión de la administración castellana en Indias y con el desarrollo de las actividades mercantiles, al igual que con la explotación de grandes y pequeñas propiedades.

A pesar de las variaciones cuantitativas, de índole coyuntural, el trasvase poblacional tenderá a mantenerse durante el setecientos como una constante. Pero, realmente: ¿estos vascos que emigran a América se enfrentan a una situación novedosa?, ¿crean, por ello, mecanismos propios para afrontar esta aventura de la "carrera de Indias"?. Para poder responder a estas preguntas, con antelación, debemos referirnos a la realidad presente en el propio territorio original de los emigrantes, ya que existía una amplia experiencia migratoria vasca, principalmente destinada hacia otras áreas del territorio peninsular desde la Edad Media, que concretará un compuesto de experiencias de gran relevancia. El mantenimiento de la afluencia de personal desde tierras vascas hacia Castilla nos lleva a presuponer la existencia de unos mecanismos que, al haber sido expuestos a las dificultades innatas de cualquier traslado migratorio, habían sido depurados por su propia puesta en práctica y se habían mostrado capaces para alcanzar unos objetivos precisos, esto es, una rápida y efectiva integración en el nuevo territorio. Este brillante éxito condicionará que, en su paso hacia el espacio americano, sea posible la utilización de los mismos mecanismos.

$\mathrm{La}$ transcendencia del movimiento emigratorio vasco en el antiguo régimen, se advierte singularmente por medio de una rápida mirada a los listados de personal, tanto en territorio americano como castellano, localizado en áreas claramente estratégicas. ${ }^{6}$ Como ya se ha advertido con anterioridad, el siglo XVIII se caracteriza por ser un período en el que se aglutinan el aumento de las posibilidades económicas de los nuevos territorios $\mathrm{y}$, sobre todo, el auge de las posibilidades de hacer carrera en la

5 Evidentemente esta precisión afectaría de manera bien diferente a unas y otras áreas, las que son de nuevo descubrimiento y las que llevaban integradas desde el primer momento.

6 En la Península Ibérica, estos focos de presencia se concretan en el mundo mercantil del XVIII (los puertos habilitados al comercio indiano como Cádiz y Sevilla) y en el centro administrativo de la nueva Corona (Madrid). Heredia Herrera, Antonia. Sevilla y los hombres del comercio (1700-1800). Sevilla: Colección Galería, 1989 y Ruiz Rivera, Julián B. El Consulado de Cádiz. Matrícula de cargadores (1730-1823). Cádiz: Diputación de Cádiz, 1988. Sobre el mundo administrativo, concentrado en Madrid, no existe una obra específica, pero sí trabajos sobre los escalafones más elevados de los órganos administrativos que pueden servir como ejemplo. Escudero, José Antonio. Los Origenes del Consejo de Ministros en España. Madrid: Editora Nacional, 1979. 
administración borbónica instalada en estos territorios. ${ }^{7}$ Una vez confirmada su presencia, debe afrontarse el análisis de los mecanismos usados por estos colectivos para su instalación, para lograr mantener contactos con su área original y alcanzar su inserción en el territorio receptor. Desde el primer momento, para cumplir estos objetivos, es imprescindible contar con unos requisitos mínimos relativos a la organización del colectivo emigrante, que no aparecen descritos en los listados de personal que indican su presencia en Indias.

Hablamos de unos requisitos o cualidades capaces de ofrecer al colectivo ciertas expectativas referidas a la plasmación de una unidad de definición y de acción, que les faculte para no fracasar en su instalación en el nuevo territorio, a la par que sean lo suficientemente eficaces como para permitir alimentar los nexos comunicativos con su lugar de origen. A nuestro entender, al menos durante el antiguo régimen, no se produce la elaboración de ningún tipo de mecanismos precisos o específicos para la consecución de los designios descritos. Más bien todo lo contrario, ya que los medios que emplearán son los que están latentes en la misma base organizativa social vasca, no contestando tanto a la solución de una específica problemática de instalación en un nuevo espacio sino, más bien, mostrándose como una respuesta lógica como reflejo de la dinámica social en que se sitúan los colectivos e individuos en sus territorios originales.

Es imprescindible precisar que este personal emigrante vive en una sociedad de índole corporativo, de la que no tiene la intención ni la posibilidad de evadirse. ${ }^{8}$ Así, Pablo Fernández Albadalejo, muestra cómo "el entramado social vasco se entiende mucho mejor cuando se aborda en términos de comunidad que en los de sociedad. Allí donde se produjo, la emergencia de esta sociedad se hizo al precio de llevarse por delante la serie de elementos

\footnotetext{
Vázquez de Prada, Valentín y Bosco Amores, Juan. "La emigración de navarros y vascongados al Nuevo Mundo y su repercusión en la comunidad de origen”. In: Arana Pérez, Ignacio (Coord.). Los Vascos y América. Madrid: Espasa-Calpe, 1990, p. 110.

El análisis de los rasgos corporativos en el ámbito social europeo está adquiriendo un nuevo prisma y una fuerte revitalización a partir de la recuperación de parte de la obra clásica del historiador austriaco Otto Brunner. A modo de ejemplo véase: Brunner, Otto. Estructura Interna de Occidente. Madrid: Alianza, 1991, y el trabajo, en una línea similar, de Gerhard, Dietrich. La Vieja Europa. Factores de continuidad en la Historia Europea (1000-1800). Madrid: Alianza, 1991. Esta historiografía ha sido, en gran medida, recuperada por la línea histórica italiana representada en la figura del historiador Piero Schiera. Véase, igualmente, la defensa sobre el concepto "holista" de estas sociedades en el trabajo del sociólogo francés Dumont, Louis. Ensayos sobre el individualismo. Madrid: Alianza, 1987.
} 
comunitarios, corporativos y estamentales que configuraban la constitución política y social a la vez del antiguo régimen"". Una sociedad, en la que el peso de los lazos familiares, clientelares, de paisanaje, amistad, patronazgo, etcétera, se encuentra en la misma base de su estructura y que mostraban, repetidamente, su valía, al hacer frente de modo positivo a las dificultades que surgen en el camino de la comunidad. ${ }^{10}$

No considerar el valor de estos mecanismos genera una primera dificultad al analizar cualquier proceso de emigración en el antiguo régimen, ya que los grupos o individuos emanados de esta sociedad corporativa, no pueden ser comprendidos como agentes independientes o absolutos, no son "ciudadanos", sino que llevan en sus espaldas un amplio componente de mecanismos que utilizan tanto en el proceso de su autodefinición como en el de instalación en el nuevo espacio. Otra precisión imprescindible radica en comprender que, en la sociedad del setecientos, no existe una división clara entre lo privado y lo público, ni entre las funciones personales y las públicas. ${ }^{11}$

Por lo tanto, el componente social no puede definirse como un agregado de agentes individuales, sino como parte constitutiva de un cuerpo o, con mayor frecuencia, de numerosos cuerpos. Esta percepción corporativa, de la sociedad del antiguo régimen, ha contribuido, sin lugar a dudas, a complicar el paisaje de definición de la misma al admitir la presencia de un numeroso agregado de cuerpos y/o comunidades de diferente carácter y valor. ${ }^{12}$ Una persona oriunda de territorio vasco se define en relación a su comunidad que, básicamente, coincide con una división geográfica

9 Fernández Albadalejo, Pablo. "El País Vasco: algunas consideraciones sobre su más reciente historiografía". In: Fernández, Roberto (ed.). La España del siglo XVIII: Homenaje a Pierre Vilar. Barcelona: Crítica, 1987, p. 558. Del mismo autor, sobre la relación entre la desaparición del mundo corporativo y la apertura de una sociedad significada por la presencia de un agregado atomístico de individuos, y, con ello, de la aparición de un auténtico "estado" véase: "El absolutismo y la transición política". Zona Abierta, n² 30 , 1984, p. 63-75. En una línea similar cabe destacar el atrevido e interesante trabajo de Portillo Valdés, José María. Monarquía y gobierno provincial. Poder y constitución en las Provincias Vascas (1760-1808). Madrid: Centro de Estudios Constitucionales, 1991.

11 Sobre la importancia de este tipo de redes de relaciones cabe destacar el trabajo de Atienza Hernández, Ignacio. "Pater familias, señor y patrón: oeconómica, clientelismo y patronazgo en el Antiguo Régimen". In Pastor, Reyna (comp.). Relaciones de poder, producción y parentesco en la Edad Media y Moderna. Madrid: CSIC., 1990, p. 411-459.

"Atienza, op. cit., p. 413.

${ }^{12}$ Sobre el sentido del sistema o concepción corporativa, véase: Redondo, Agustín (coord.). Le Corps comme Métaphore dans l'Espagne des XVI et XVII siècles. Tours: Presses de la Sorbonne Nouvelle, 1992. 
(definida bajo un prisma histórico). A pesar de esta inicial unidad del criterio de definición, también es cierto, que la diversidad de comunidades, determinadas por un carácter geográfico, es muy amplia. ${ }^{13}$ Por otro lado, debemos estar atentos a la consideración que, durante el antiguo régimen, contempla la complejidad del individuo, ya que también se adscribe, y con ello conforma parte de su propia definición, en las asociaciones (gremios, cofradías, vecindades, Real Sociedad Bascongada de Amigos del País, etc.) de las que forma parte, en la familia a la que pertenece, respecto a los títulos que posee y otros "ítems" de igual relevancia. De esta manera, la nueva realidad ofrece una amplia dinámica de puntos de análisis no limitados a un origen geográfico o una adscripción nacional, como ocurrirá en períodos posteriores.

Al estudiar los lazos emanados de las relaciones que estructuran la base social del lugar de origen, y que definen al individuo en estrecha relación a un cuerpo o cuerpos, es posible entender cómo estos lazos, o redes de relaciones, eran los más operativos para el logro de sus fines en las nuevas áreas. No debe entenderse que este personal cuente con la posibilidad de elegir esos mecanismos, sino que mas bien, o utiliza los medios "ortodoxos" o las posibilidades que cuenta para efectuar el traslado e integrarse en la nueva área serán mínimas. A pesar de que venimos hablando de un colectivo concreto, con un lugar de origen preciso (el País Vasco) veremos cómo, sus componentes, al elegir los medios de ayuda siempre buscarán los más próximos, o mejor conocidos, de manera que, por ejemplo, los lazos de paisanaje serán más fuertes entre quienes provienen de una misma comunidad (ciudad, pueblo, anteiglesia, valle o provincia vasca) que los referidos a un paisanaje más amplio (vasco o castellano), aunque, en su defecto, estos últimos también serán empleados.

Es fácil encontrar cómo en ciertas áreas de recepción el paisanaje, siempre que sea posible, se tiende a establecer a niveles de comunidades o cuerpos muy precisos más que a niveles de entidades superiores que, incluso en ciertos casos, todavía no existen. Este cúmulo de aspectos es lo que le confiere a la emigración vasca un carácter específico, una particularidad que es

13 Por poner unos ejemplos de entidades geográficas e históricas, existentes en el setecientos, podemos destacar: el Reino de Navarra; las provincias de Alava, Guipúzcoa y Vizcaya; las ciudades de Vitoria, Bilbao, San Sebastián, Pamplona o Bayona, y un innumerable componente de valles, anteiglesias, merindades, hermandades, barrios, y pueblos de diferentes tamaños y peso estratégico. 
imprescindible considerar al estudiar cualquier proceso migratorio dirigido por estos agentes sociales. ${ }^{14}$

$\mathrm{Al}$ analizar el componente de origen vasco en el centro administrativo castellano (Madrid) o en los puertos comerciales más relevantes de Castilla (Cádiz y Sevilla) se venía advirtiendo algo similar. Acompañando a la presencia de individuos de origen vasco en estas localidades, en cuanto su número o su prestancia en la nueva área se lo permitían, veremos cómo instauraban organismos capaces de ayudar a conferirles una unidad de definición y acción. El primer carácter de estos asociaciones es el de un marcado sentido asistencial y religioso, aunque en su interior tiendan a mostrarse, al unísono, como privilegiados ámbitos de solidaridad y sociabilidad para el personal que se encuentra alejado de su "patria". ${ }^{15}$ A nivel peninsular, el desarrollo de mecanismos capaces de definir y de hacer operativo a un colectivo están íntimamente ligados a estas asociaciones. A partir de ellas, se genera un mundo de relaciones que ayuda a organizar y gestionar la venida, integración e identidad de los recién llegados a estas áreas. De estas asociaciones caben destacar, entre otras muchas: la Real Congregación de San Fermín de los Navarros y la de San Ignacio de los Vascos en Madrid, la Congregación de Nuestra Señora de la Piedad de Sevilla o también denominada de los Vizcaínos, la Cofradía del Cristo de la Humildad y Paciencia en Cádiz. ${ }^{16}$ Otro tanto ocurrirá con instituciones de índole parejo que se establecen en territorio americano.

" Así se muestra como característica peculiar de esta emigración, la pervivencia de una "solidaridad etnorracial", esto es, de una solidaridad de grupo. Vázquez de Prada, op. cit., p. 104. Esta visión, ya venía siendo referida desde principios de siglo, identificándolo bajo un término diferente, aunque refiera una misma realidad: "l'esprit de corps". Un espíritu de cuerpo ligado a la lengua, a la pertenencia a valles cerrados y otras características. Landhe, Pierre. L'Emigration Basque. Paris: Nouvelle Librairie Nationale, 1910, p. 152. Frias, Susana R. "Aproximación Metodológica al estudio de una parcialidad étnica. Los Vascos de Buenos Aires. 1580-1713”. Res Gesta (Separata), EneroJunio, 1991, p. 977-108.

15 El término "patria", debe entenderse de manera independiente a nuestra actual concepción, ajeno a matices de carácter nacional. Así, durante el antiguo régimen, un habitante de la Anteiglesia de Begoña (Vizcaya) se refiere a su población nativa como la "República" de Begona, a la cual la define como su patria. Así, el término "patria" indica, todavía en el siglo XVIII, simplemente la pertenencia o adscripción a un territorio, el de nacimiento, sin connotaciones de carácter estatalista. Sobre el valor de estas entidades, en su papel socializador, destaca el trabajo colectivo titulado: Les Sociétés Fermées dans le Monde Ibérique. Paris: CNRS, 1986.

${ }^{16}$ Caro Baroja, Julio. La hora navarra del XVIII (Personas, familias, negocios e ideas), Pamplona: Diputación Foral de Navarra, 1966; sobre la asociación vasca fundada en 1713 en la villa y corte de Madrid la obra Noticia del origen, fundación, objeto y constituciones de la Real Congregación de naturales y originarios de las tres Provincias 
Sin olvidar el carácter vocacional de las corporaciones citadas, es evidente que en su transfondo se muestran, o al menos se utilizan, como medios capaces de crear un ambiente donde crear, mantener y estimular los lazos entre individuos que provienen de diferentes cuerpos. De esta manera, estas asociaciones actúan como foros que reproducen los mecanismos ya conocidos en el ámbito social de origen. En este foro se integran, sin mostrar ningún tipo de fricción, otros mecanismos ajenos al paisanaje como los lazos clientelares, de amistad, de patronazgo y, sobre todo, los familiares.

Estos últimos lazos, los familiares, se muestran como la vía más operativa en la sociedad del antiguo régimen al desplegar el proceso migratorio y fundamentalmente el de instalación e integración en un nuevo territorio. Los mecanismos de la ayuda familiar están presentes, con diferentes grados de relevancia, en la mayor parte de los casos particulares de emigración. ${ }^{17}$ La ayuda de la familia, tanto directa como paralela (cuñados, suegros, padrinos), se convierte en una vía básica para quienes planean su desembarco en una plaza en la que no tienen contactos y de la que tampoco conocen ni su estructura ni su dinámica de funcionamiento. En el papel de introductor, de ayuda o valedor, la acción del familiar se convierte en un mecanismo transpolado del mundo peninsular. En gran parte del componente vasco, el proceso ya aparecía en el

Vascongadas, establecido bajo la advocación del glorioso San Ignacio de Loyola. Madrid: Imprenta de Hernández, 1896; igualmente, a falta de obras específicas sobre las asociaciones vascas en ciudades como Cádiz o Sevilla, véase el trabajo de Garmendia Arruebarrena, José, "Alava en las Congregaciones o Hermandades vascas fuera de las Provincias". In: La Formación de Alava (tomo I). Vitoria: Diputación Foral de Alava, 1985, p. 403-426.

17 En este sentido el citado trabajo de Julio Caro Baroja muestra altamente ilustrativo, al analizar el proceso de instalación de los navarros (principalmente provenientes del valle del Baztán) en la corte madrileña y en otras esferas de poder durante el siglo XVIII. Es una especie de toma de poder de algunos de los órganos directivos de la monarquía castellana del XVIII, en el que el valor del vínculo familiar se convierte en paradigmático. En este sentido cabe destacar el minucioso trabajo realizado por Janine Fayard sobre un órgano de especial relevancia en la vida política castellana como es el Consejo de Castilla. Los Miembros del Consejo de Castilla (1621-1746). Madrid: Siglo XXI, 1982. La culminación de este trabajo se encuentra en: "Los Ministros del Consejo Real de Castilla (1746-1788)". Cuadernos de Investigación Histórica, nº 6, 1986, p. 109-137. El valor de la familia en estos procesos de integración venían siendo significativos desde la Baja Edad Media, así como en los siglos XVI y XVII, como muestra los trabajos de García Marín, José. La burocracia castellana bajo los Austrias. Madrid: INAP, 1986; y El oficio público en Castilla durante la Baja Edad Media. Madrid: INAP, 1987. Véanse igualmente los trabajos de Pilar Gonzalbo Aizpuru, como coordinadora en Familias novohispanas. Siglos XVI al XVII. México: Colegio de México, 1991; y autora en La familia en el mundo iberoamericano. México: UNAM, 1993. 
primer traslado efectuado hasta los puertos marítimos andaluces (Cádiz y Sevilla) antes de dar el paso definitivo a las Indias. ${ }^{18}$

Los vínculos ficticios (clientela, amistad, patronazgo o simples recomendaciones), que no vienen impuestos al individuo como los lazos familiares, también muestran su operatividad en el proceso de emigración a América, así como lo habían hecho en el transcurso del traslado e integración del personal vasco en la administración castellana. Los peligros y dificultades que debe afrontar el emigrante en el nuevo espacio se reducen, si no se consiguen eliminar, gracias a estos mediadores que pueden actuar desde el nuevo territorio, donde están instalados, como desde el lugar de origen. Es frecuente encontrar referencias a la búsqueda de ayudas y recomendaciones, que en muchos casos encubren procesos de patrocinio y clientelismo, en gran parte de los individuos que emigran a las Indias.

En general, el conjunto de mecanismos que forman parte de la estructura corporativa durante el siglo XVIII en territorio vasco, fueron explotados por sus oriundos durante todo el antiguo régimen en el momento de trasladarse a nuevas áreas, lejanas (América) o próximas (Madrid), esto es, en cualquier proceso migratorio y de integración. Unos mecanismos que responden a la estructura organizativa de la sociedad del setecientos, que permiten a este personal afrontar con expectativas alagüeñas las nuevas dificultades que origina un espacio desconocido. Los mismos mecanismos de integración que se concretan en el lugar receptor no

15 Tomás Ruiz de Apodaca (natural de Manurga, Alava), con catorce años de edad, y Julián Martínez de Murguía, salen en dirección a Cádiz en 1716. En esos años, al igual que estos mozos, parece existir un continuo trasiego de pajes y mozos, provenientes de las provincias vascongadas, que pretenden integrarse en el entramado mercantil de estas ciudades meridionales de Cádiz y Sevilla. En los primeros momentos, Tomás, contó con el invalorable apoyo y, sobre todo, protección de sus paisanos, Pedro y Andrés Martínez de Murguía, oriundos del pequeño pueblo alavés de Manurga. A la hora de solicitar licencia para poder embarcarse a Indias, hubo de someterse a un juicio declaratorio en el que participaron como testigos a su favor, Ramírez de Aguilar (natural de Vitoria, capital de Alava), Celedonio de Zaldós (de Echagüen, Alava) y su compañero de viaje Julián Martínez de Murguía (natural de Manurga). Garmendia Arruebarrena, José. Tomás Ruiz de Apodaca, un comerciante alavés con Indias (1709-1767). Vitoria: Diputación Foral de Alava, 1990. En todo el proceso integrativo en una nueva área, los lazos de paisanaje que vehiculan, de manera efectiva, las necesidades de estos jóvenes no se circunscriben al área de las provincias vascas, sino que, tienden a limitarse, en gran medida, a un paisanaje de valle e, incluso, de la localidad de donde son nacidos y donde, recordemos, sigue viviendo su familia como punto de referencia. En esta misma línea, la importante familia de los Aycinena contaba con contactos en la Península Ibérica, concretamente en Navarra, que, en gran medida, se basaban en vinculaciones familiares. Balmori, op. cit., p. 86. 
vienen a ser más que una recreación, más o menos ortodoxa, de las pautas que conocían y venían desarrollando en sus lugares de origen.

\section{Los mecanismos de emigración e integración en los nuevos territorios}

En las primeras páginas de la obra de Pierre Landhe sobre la emigración vasca, se hace la siguiente afirmación: "Pour être un Basque authentique, trois choses sont requises: porter un nom sonnant qui dise l'origine; parler la langue des fils d'Aïtor, et [...] avoir un oncle en Amérique". "Sin lugar a dudas, es sintomática la composición de este triunvirato de cualidades, en las que además de concluir la presencia de los rasgos definitorios de un colectivo determinado (el origen geográfico y cultural así como la lengua) se agrega la expresión práctica de un hecho histórico de gran relevancia en la vida de esta comunidad. En esta segunda parte, vamos a intentar mostrar la operatividad que ofrece un cuerpo o fuente documental a la hora de establecer un preciso análisis de los mecanismos y medios de integración que se establecen al proceder a la aventura de emigrar a las Indias en el siglo XVIII.

Estamos refiriéndonos a la correspondencia epistolar que se establece, tanto entre los emigrados y aquellos que se quedaron en las tierras de origen, como en las referencias de tipo indirecto que se reflejan en las mismas misivas. ${ }^{20}$ Una correspondencia particular o personal que, aunque falta de una estructura bien definida, se caracteriza por ofrecer al investigador una multiplicidad de informaciones de gran importancia. A través de estas manifestaciones subjetivas de los autores de estas cartas se aprecia, con singular nitidez, el valor de ciertos agregados a la hora de proceder al traslado a un nuevo espacio.

En una de estas cartas se expone una referencia moral a la concepción estante a mediados del siglo XVIII sobre quienes vuelven de los territorios americanos, en los siguientes términos:

${ }^{19}$ Op. cit., p. XVII. El subrayado es nuestro. De manera más folklorista define otro autor decimonónico una percepción similar, veamos dos ejemplos: "Quien hable el vascuence tiene adelantado la mitad del camino" y "Más que la mejor carta de recomendación vale una boina". Cola y Goiti, José. La Emigración Vasco-Navarra. Vitoria: Imprenta de la Viuda e Hijos de Iturbe, 1883, p. 83. Este último autor, pone de manifiesto el mantenimiento del mecanismo de las cartas de recomendación en el proceso migratorio.

${ }^{20}$ Otte, E. Cartas privadas de emigrantes a Indias, 1540-1616. Sevilla: Junta de Andalucía, 1988. 
"creen muchos que basta venir de Yndias para traer montantadas, y se engañan del todo porque todo lo ignoran, y han de reflexionar que el que mira al principal fin manteniendo su conciencia limpia es limitado lo que puede hacer y el que no mirare este respeto hara mucho mas pero vivira y morira engañado que es lo peor". ${ }^{21}$ Es evidente que la principal razón del paso a los territorios americanos se concreta en la consecución, a través de cualquier medio, de un fin determinado: el enriquecimiento y logro de gracias y mercedes que le permitan reintegrarse en su lugar de origen en una situación más favorable. El contacto o conexiones continuas con el lugar de salida, están íntimamente vinculadas a la pervivencia de un fuerte interés por volver enriquecido y gozando de una mejor consideración social en su lugar de nacimiento.

En el mundo del setecientos, el uso del sistema de la recomendación o la encomendación a un patrón, integrándose a una red clientelar, ${ }^{22}$ es un medio de habitual empleo y, en la misma medida, su utilización, como mecanismo de ayuda y de integración, será trasladado al territorio americano. En esta línea se expresa la siguiente misiva remitida por el Conde de Superunda a su sobrino Félix José Manso de Velasco: "El Cavallero de las dos sobrinas casadas en esta Ciudad es bien conozido mio sin tantas señales y Amigo de toda mi confianza por lo que haviendose balido Vm. dell para que se me saque deste destierro ... me dice que hallandose con noticia de haverse mandado tirar despachos de Virrey del Peru con el nombre en blanco suponia mi buelta muy proxima [...] el recomendado de Vm. Don Joachin de Olivarren, ha pasado de Sachristan mayor a Capellan Real deesta Capilla que es lo que apetecia y lo que un

${ }^{21}$ Archivo del Territorio Histórico de Alava. Fondo Samaniego. Caja $92 \mathrm{n}^{2} 2$. Carta de Martín Sáenz de Tejada a Félix José Manso de Velasco. Madrid. 28/abril/1763. Es una misiva dirigida por el administrador de la casa de los Manso de Velasco, que se encuentra en Madrid llevando los negocios y administrando las propiedades de esta familia asentada en la zona de Laguardia (Alava). Una familia, en la que uno de sus miembros, José Antonio Manso de Velasco (Conde de Superunda), llega a ser Virrey del Peru. Véase: Moreno Cebrián, Alfredo. Relación y Documentos del Gobierno del Virrey del Perú, José A. Manso de Velasco (1745-1761). Madrid: CSIC, 1983. Ochagavía Fernández, Diego. "El I Conde de Superunda". Berceo, LVIII, 1961, p. 25-49.

22 Este hecho es paradigmático, desde períodos anteriores, en el ámbito territorial de la vieja Europa. Véase al respecto el trabajo de Kettering, Sharon. Patrons, brokers and clients in Seventennth-Century France. New York: Oxford University Press, 1986. De esta manera, es posible comprender como los ministros del rey o validos de los Austrias Menores (el Conde Duque de Olivares o el Duque de Lerma) eran, al unísono, "cabezas de unas casas a las que debían conservar, y en la medida de lo posible, elevar". Feros, Antonio. "Lerma y Olivares: la práctica del valimiento en la primera mitad del seiscientos". In: Elliott, John y García Sanz, Angel (coords.). La España del Conde Duque de Olivares. Valladolid: Universidad de Valladolid, 1990, p. 200. 
Virrey puede dar por si solo sin concurso de Arzobispo". ${ }^{23}$ La continua comunicación con su familia, estante en la península, le permite alargar el brazo para dirigir desde su fuente de poder su carrera administrativa. $Y$, al mismo tiempo, responde con la puesta en favor de su familia, amistades y clientes, de todos los mecanismos que encuentra en sus manos. El recomendado, como su propio nombre indica, es de un claro origen vasco.

El mismo proceso de ayudas y recomendaciones establecido por medio de la familia y la clientela, se utiliza en el proceso de integración y emigración. Así recibe Félix José Manso de Velasco esta carta de Joaquín Sánchez, un cliente suyo, que será respondida positivamente adjuntando las cartas pedidas: "estando para pasar a Yndias a continuar su servicio Real mi primo Don Francisco Ybago hijo de Don Vicente Ybago de el Ciego estimare me remita una carta de fabor para el Virrey". " De esta singular manera, el viaje al nuevo territorio y las primeras dificultades, se solventan por medio de la localización de un apoyo directo en esta área. Una protección que se comprende como imprescindible para el buen éxito del negocio o aventura. ${ }^{25}$

Este sistema de recomendaciones no debe entenderse como algo específico de unas redes clientelares asociadas a las familias de mayor relevancia, sino que incluso en aquellas asociaciones, que son actualmente celebradas como la punta de lanza de la modernización y transformación de la sociedad vasca del siglo XVIII, encontramos paralelismos de igual signo. Así, una asociación como la Real Sociedad Bascongada de Amigos del País se encuentra ante la, no inusual, petición de una persona vinculada a ella, Ramón Damián de Borica (natural de Bilbao), que había obtenido el premio de las Escuelas Públicas, creado y organizado por esta asociación, en una misiva dirigida a esta institución. Afirma, que se encuentra en un momento en el que necesita "ocuparse en la Carrera de Yndias y seguirla a fin de probar fortuna en aquel desttino (a que se inclina)

${ }^{2}$ ATHA. Fondo Samaniego. Caja $91 \mathrm{n}^{2} 2$ 2. Lima. 15/Octubre/1757. El subrayado es nuestro.

${ }^{24}$ Idem, $n^{9}$ 2. Elciego (Alava). 29/abril/1758.

` La ayuda recibida por los clientes y amigos de la casa y familia de los Manso de Velasco, se advierte singularmente en el siguiente texto: "porque quando discurri merezer de la benignidad de V.E. la honrra de quele manifestase mi gratitud a los particulares favores que merezi a su Generosidad, en el feliz y azertado Govierno que obtuvo en la Presidenzia de Santiago de Chile ... Rendidamente suplico a V.E. se sirva de perdonar mi atrevimiento, y mandarme en todo quanto fuere de su mayor satisfazion». Idem, caja $39 \mathrm{n}^{0}$ 17. Carta de Francisco Rodrigo de Vidal a José Antonio Manso de Velasco. Buenos Aires. 20/Mayo/1748. 
se ve en la precisa y urgente consttitucion de impetrar rendidamente el auxilio y patrocinio" de esta sociedad. Por ello, pide que le ayuden mediante el "recomendarle para el mas feliz exitto de su desttino a los Yndividuos de la Real Sociedad que puedan protexerle en la citada Carrera de Yndias para que de esta suerte con su amparo y proteccion: logre los adelantamientos y felicidades que anhela". "Los términos empleados en esta carta remitida a la Real Sociedad Bascongada de Amigos del País (ejemplo propuesto como máxima expresión de la implantación de las ideas ilustradas y modernizadoras en territorio vasco), muestra el valor de los lazos corporativos, a los que se unen los puramente clientelares sin fricción alguna.

Es evidente que, Ramón Damián de Borica, pretende valerse de los contactos que ofrece la Bascongada a cualquier vasco, que vinculado a ella, pretendiera hacer la carrera de Indias. Pero, igualmente, esta asociación sabe perfectamente que al ofrecer su ayuda a este individuo contará con un adherido más en territorio americano, que actuará en su favor cuando, de nuevo, sea necesario mandar a otra persona o, que si entra en la administración, para lograr su ayuda en el momento oportuno. Pide, en definitiva, la posibilidad de contar, antes de iniciar el viaje, con el apoyo y, sobre todo, con la ventaja de integrarse en un colectivo definido por su pertenencia al territorio vasco y a una misma asociación. $\mathrm{La}$ Bascongada intenta integrar a los individuos pertenecientes a otras asociaciones, como la Congregación de San Ignacio de los Vascos de Madrid, para fomentar su operatividad en los territorios ajenos al País Vasco (la corte madrileña). ${ }^{27}$

En todo momento, esta asociación, basada en un personal de origen o relacionado con el terruño vasco, fomenta la integración de personas que puedan ser útiles a sus expectativas. ${ }^{28}$ En esta misma dirección se entiende la misiva remitida por Martín de Sarratea (Vicerrecaudador y Comisionado de la Sociedad en Buenos Aires) al

${ }^{26}$ Idem, Fondo Prestamero. Caja $33 n^{2} 19$. Bilbao. 5/Febrero/1773.

27 Así Juan Bautista Porcel (Comisionado de esta sociedad por la provincia de Alava) se dirige al Conde de Peñaflorida, de esta manera: es necesario "convidar a nuestros individuos por medio de los Estractos a que se agreguen a la Cofradia". Idem, caja 37 n $^{9}$ 42. Vitoria. 31 /diciembre/1775.

${ }^{28}$ Así se expresa Ignacio Nuñez de Gaona: "El Rey se ha servido conferirme una Plaza de la Sala del Crimen de la Real Audiencia de Barzelona, y deseando yo ofrecer a la Sociedad este empleo i sus facultades, en credito de mi filial amor i gratitud se lo aviso a V.S. para que por su medio tenga esta noticia i yo la satisfaccion de ofrezerme tambien, a su obediencia". Idem, Documentación Histórica. Legajo $1.015 \mathrm{n}^{2}$ 15. Madrid. $15 /$ febrero/1775. 
Marqués de Montehermoso: "he hecho saber a los Paysanos corresponsales en el Reyno de Chile y las Provincias del Peru pertenecientes a este virreynato, la dignacion de la Real Sociedad, y les he recomendado eficazmente el obgeto de conmover el amor Patriotico de los amigos esparcidos en aquellos remotos Payses". ${ }^{29}$ Es un criterio básico para el buen funcionamiento de esta organización el mantener al mayor número de personas, siempre que cumplieran con unas condiciones, integradas bajo su manto.

Una asociación caracterizada, en teoría, por su carácter ilustrado y racional pasa a convertirse en un instrumento más de los empleados por los individuos de origen vasco que emigran a américa en su empeño por enriquecerse y adquirir gloria. Un instrumento que se conjuga con otros mecanismos como los referidos a la familia, la amistad, el puro y exclusivo paisanaje y el clientelismo. Dentro de este conglomerado de relaciones y líneas de vinculación efectivas, el papel jugado por el personal adscrito al comercio y tráfico marítimo con américa, de origen vasco, es de singular importancia. En esta dirección dos comerciantes, Agustín de Uztariz y Juan Bautista de Casabona, vinculados con el Virrey del Perú, José Antonio Manso, se remiten misivas entre las cuales hemos podido entresacar informaciones muy jugosas. En ellas puede advertirse cómo los lazos familiares y los de amistad (que, en ciertas ocasiones, encubren fórmulas clientelares) se convierten en la dínamo que mueve parte del proceso mercantil y de asentamiento en las plazas mercantiles del área americana.

En una misiva de Agustín de Uztariz a Juan Bautista de Casabona le dice cómo ha encargado a Martín de Zelaietta la compra en el Callao de 9 a 10 cargas de cacao de Guayaquil en un barco que "a de despachar un amigo, y en el que devera hir de sobrecargo un primo mio ... estimare concurra Vmd. a estte fin fazilittando qualquiera empeño que se necesario para la preferencia a que quedare agradezido". ${ }^{30}$ En un mero trato mercantil, como es el transporte de una cantidad de cacao a la península, se integran factores ajenos al hecho puramente económico, trascendiendo a mostrarnos unas características básicas sobre el proceso de organización de estos mercaderes y del tráfico mercantil que promueven. Unos comerciantes que también se emplean, en favor

Idem, Fondo Prestamero. Caja $38 n^{2}$ 15. Buenos Aires. 28/Marzo/1787. Esta acción viene como resultado de la recepción de los impresos de esta sociedad a través de los comerciantes, de origen vasco, Agustín Casimiro de Aguirre y Francisco Ignacio de Ugarte. El subrayado es nuestro.

30 Idem, Fondo Samaniego. Caja 39 n² 18. Cádiz. 26/noviembre/1750. El primo es Juan Francisco de Micheo y Uztariz. 
de su patrón, José Antonio Manso, ofreciendole informaciones precisas sobre la situación de la corte y convirtiéndose en un instrumento de primer orden a la hora de comunicar la corte peninsular con los altos cargos de la administración americana. ${ }^{31}$ Ambos actores, patrón y clientes, se favorecen de una vinculación efectiva que permite una rápida integración de ambos en la realidad de los nuevos territorios.

El ámbito mercantil se encuentra muy necesitado de estos mecanismos ya que, tanto la disposición organizativa de la casa mercantil como la de las líneas en que se sustenta el tráfico, se armonizan por medio de unas redes de relaciones en las que es preciso contar con personas de confianza que ocupen los diferentes lugares. En esta línea, Guillermo Lohmann Villena, advierte cómo los hombres de empresa de raigambre vasca en Perú, entendieron que era "indispensable hacer caudal de la coexistencia de un enjambre de paisanos instalado en destinos claves de la administración pública y fiscal, ejerciendo ministerios de alta responsabilidad u ocupando dignidades de gran relieve social". ${ }^{32}$ Con el paso del tiempo, los ocupantes de estos cargos acaban integrándose, por medio de la vía matrimonial, dentro de la propia estructura de la casa mercantil.

Por ello, es fácil advertir como un agente o comisionado de una casa mercantil termina casándose con alguna de las hijas del propietario de la misma e integrándose de manera efectiva en ella (o, en todo caso, con otra familia) y en la casa mercantil. ${ }^{33}$ Los mismos grupos de comerciantes, que provenientes de la península se establecen en los diferentes territorios americanos, deben desarrollar una ágil política matrimonial que les permita integrarse dentro de las líneas del organigrama mercantil que domina cada territorio y cada actividad comercial. Es frecuente encontrar en los

" Le informan de que el Marqués de la Ensenada y Ricardo Wall se habían reconciliado en sus disputas y cómo, en estos momentos, se hallaban "a partir un confite". Igualmente, le habla de las favorables conexiones de Ensenada con el rey "entrando frequentemente en el Cuarto del Rey". Se despide afectuosamente sin dejar por ello de omitir su adscripción como cliente a su patrón con la siguiente expresión: "Esta a los pies de V.E. su mas rendido, fiel criado". Idem, n²3. Cádiz. 4/agosto/1762.

${ }^{32}$ Lhomann, op. cit., p. 58. Unos comerciantes que, de hecho, consiguen controlar el organismo representativo de su profesión: el Consulado Limeño. Los rasgos que unifican a los miembros de este colectivo, definido por Lhomann como una "plutocracia", se establecen en base a dos factores cohesivos primordiales: el parentesco y la común oriundez. Idem, p. 61.

33 Balmori, op. cit., p. 85. Este es el caso de los Aycinena, en Centroamérica, que por medio de una política matrimonial efectiva consiguen, en poco tiempo, hacerse con la mayor parte del comercio local. 
documentos notariales cómo los socios de las compañías comerciales formadas por un vasco (tanto a nivel peninsular como americano) son también de origen vasco, al igual que los testamentarios, albaceas, prestamistas, etcétera, de manera que, a partir de una mera acción económica, podemos advertir el funcionamiento espectacular de los mismos mecanismos que son utilizados durante el proceso migratorio.

En el mismo transcurrir, la llegada de familiares de las provincias vascas, principalmente por medio de la relación tíosobrino, se convierte en un medio de gran prestancia a la hora de emigrar a estos territorios. ${ }^{34}$ Un ejemplo práctico de esta relación tíosobrino se expresa en la trayectoria de la familia ayalesa de los Urrutia. Juan de Urrutia emigró a las Indias donde fue, poco a poco, preparando "el camino a su sobrino don Juan Antonio", y siguiendo este vía, la culmina en 1689 concediéndole el título de Marqués del Villar del Aguila. ${ }^{35}$ Entre otros sobrinos de Juan de Urrutia, llegaron a México, Sebastián Antonio Fernández de Jauregui y Urrutia (que se encargó del mayorazgo de su tío en México), Juan Antonio Fernández de Jauregui y Urrutia (llegó a ser Gobernador y Capitán General del Nuevo Reino de León y fue, también, albacea testamentario de su tío) y Agustín del Campo y Urrutia (se traslado a México donde falleció mientras estudiaba), todos ellos oriundos del valle de Ayala (del pueblo de Menagaray). ${ }^{36}$ Después, en 1729,

* La relación entre la estructura familiar existente en territorio vasco y el proceso migratorio ha sido tomado en consideración desde principio de este siglo como lo muestra el trabajo de Etcheverry, Louis. 'L'expansion familiale considéré comme source de l'expansion coloniale: l'exemple des Basques”. Réforme Sociale, XLVI, 1903, p. 799-808.

35 Ramírez Montes, Guillermina y Iturrate, José. Un ilustre alavés en México. Juan Antonio de Urrutia y Arana 1670-1743. Vitoria: Caja de Ahorros Municipal de Vitoria, 1979, p. 45-52. Samaniego, Federico de. El Marqués del Villar del Aguila. Querétaro: Cimatario, 1948. La primera consideración con el sobrino es la de traspasarle el oficio de guarda mayor de la Casa de la Moneda de México en torno a 1687. Este personaje estaba emparentado con varios vascos, principalmente de origen ayalés, estantes en México como los Miñaur, y contaban con administradores de origen vasco en Madrid (Cristóbal de Aldama, del mismo valle) y en Cádiz (Miguel de Arroyabe). Esta relación tío-sobrino se amplia en la generalidad de los diferentes lazos familiares ya que también participa el padrino así como el hermano. Un ejemplo de esta última situación la expresa el ayalés, Francisco Manuel de Aldama y Menoyo, que arribó al reino de Nueva España merced a la intervención de su hermano Pedro: «por Direccion y a espensas de el dicho nuestro hijo, y heredero". Archivo Histórico Provincial de Alava. Escribanía de Juan José de Villachica. Protocolo $\mathrm{n}^{2} 12.635 .5$ /Junio/1743. Sin foliar).

${ }^{36}$ Del mismo pueblo (en el valle norteño de Ayala, Alava) del que fueron naturales: Eugenio de Llaguno y Amírola quien, durante el reinado de Carlos IV, llegó a ser Secretario de Estado y de Despacho de Gracia y Justicia; y José Antonio de Armona y 
llegó otro pariente, Juan Antonio de Jauregui Aldama Ayala, que ostentó el título de III Marqués del Villar del Aguila.

El recién llegado cuenta, desde su arribada, con el apoyo específico de una organización, frecuentemente la casa mercantil del pariente ya establecida en la que puede, poco a poco, ir aprendiendo su trabajo e integrándose en el conglomerado de relaciones que armonizan el tráfico de cada zona. De esta manera, parte de un previo conocimiento sobre cuál es la competencia, cuál es la estructura del tráfico de un producto en cuestión, contar con una red mercantil estable y activa. Es muy frecuente que estas familias e individuos se involucren en la mayor parte de las actividades económicas de cada territorio, integrando en ellas a alguno de sus familiares, parientes y amigos consiguiendo así formar fuertes monopolios. ${ }^{37}$ Esta situación se convierte en la base fundamental que sustenta el éxito y posterior paso de estos individuos a cargos de responsabilidad política, tanto a nivel local como de la administración borbónica en Indias.

Una vez logrado cierto dominio en su situación, ya sea en los negocios o en la carrera administrativa, "el que ha tenido éxito llama a su mujer, a sus sobrinos, a sus parientes y las noticias que van llegando sobre su prosperidad son la mejor propaganda para despertar el deseo de emigrar dentro del círculo de sus allegados". 38 Deben considerarse ambos factores a un nivel parejo: la noticia del éxito económico y social incita, sin lugar a dudas, al reavivamiento de la tendencia emigradora, pero, no es menos cierto, que el conocer

Múgica. Palacios Hernández, Emilio. "Llaguno y Amírola o la ilustración como labor de Estado". Boletín de la Real Sociedad Bascongada de Amigos del País, Año XL, 1984, p. 203225. Y, del mismo autor, "José Antonio de Armona, un funcionario eficaz para el Madrid de Carlos III". Cuadernos de Alzate, n 7, 1987, p. 14-30. Los pasos seguidos por estos dos ayaleses, que hacen carrera administrativa en territorio peninsular, se asemejan, a grandes rasgos, en cuanto al peso y utilización de los mecanismos familiares, relaciones tío-sobrino, clientelismo, etcétera. Eugenio de Llaguno y Amírola estará relacionado, como agente en la corte, con la Real Sociedad Bascongada de Amigos del País además de desarrollar una interesante vida intelectual.

37 Moreno de los Arcos, Roberto. "Los Vascos en el comercio con la Nueva España". In: Escobedo, Ronald, Rivera Medina, Ana $\mathrm{M}^{\mathrm{a}}$ y Chapa Imaz, Alvaro (coords.). Los Vascos y América. Bilbao: Fundación Banco de Vizcaya, 1989, p. 137. Unos vascos que, con escasa excepciones, participan en la Cofradía de Nuestra Señora de Aranzazu (fundada en 1681) y en el Colegio de las Vizcaínas (1754). Respecto a esta última institución véase: Gárate Arriola, Justo y Tellechea Idigoras, José Ignacio. El Colegio de las Vizcaínas de México y el Real Seminario de Vergara. Vitoria: Gobierno Vasco, 1992. Martínez Salazar, Angel y San Sebastián, Koldo. Los Vascos en México. Estudio biográfico, histórico y bibliográfico. Navarra: Txertoa, 1992.

38 Mariluz, op. cit., p. 109. 
y gozar de cierta relación, del tipo que sea, respecto al triunfador hace mucho más atractiva la posibilidad de triunfar al emigrar.

Estas noticias corren por las localidades y los valles del País Vasco, quizás engrandadas y magnificadas, y tienen su más viva expresión, en los continuos procesos de creación de capellanías, reedificaciones de las iglesia en las que el benefactor ha sido bautizado, creación de arcas de misericordia, de obras pías, de obras de dotación de doncellas, de dinero para pagar una escuela y su maestro, etc. Unas acciones que se plasman en un amplísimo conjunto de edificaciones que recuerdan ávidamente el éxito conseguido en territorio americano. ${ }^{39}$ Hay que tener en cuenta que, además de estas medidas que actúan como fuentes de propaganda del éxito personal, al mismo tiempo que como expresión de la bondad y posibilidades de las nuevas tierras, en ningún momento se tienden a romper los nexos comunicativos establecidos por medio de la correspondencia y los envíos de dinero. También es frecuente encontrar a representantes de estos "americanos" ocupando, cuando les toca el turno, su puesto como mayordomos en las cofradías de sus localidades natales estrechando, de manera más profunda, sus lazos emotivos y, sobre todo, personales con el lugar de origen. ${ }^{40}$

Evidentemente, estas breves referencias extraídas, en gran medida, a partir de la correspondencia epistolar que se remite entre el emigrado y la familia estante en su lugar de origen, muestran el papel vital que juegan ciertos factores como la familia, el paisanaje, la amistad o el clientelismo, al analizar el proceso de emigración de colectivos como el vasco. Un grupo de individuos que aplica unos mecanismos, conocidos por distinguirse como los medios prácticos que estructuran la organización social en la que nacen, viven y se desarrollan y que, finalmente, tienden a conformarlos como un medio exitoso para emigrar.

Igualmente, estos mecanismos, confieren a este grupo un matiz organizativo más estricto y preciso que el utilizado por personas y sectores provenientes de otras comunidades. Un "espíritu de cuerpo", como se ha definido, que les permite ostentar una

39 Los comerciantes alaveses, oriundos del valle de Ayala, Francisco y Bartolomé de Miñaur contribuyen a reparar el retablo del Santuario de Nuestra Señora de la Blanca. Ramírez Montes, op. cit., p. 54. En torno al efecto que tienen en el arte sacro las donaciones de dinero por parte de estos personajes emigrados a américa, véase, Portilla, Micaela J. Catálogo Monumental de la Diócesis de Vitoria (6 tomos). Vitoria: Caja de Ahorros Municipal de Vitoria, 1988.

40 En 1698 Francisco de Miñaur hace las veces de mayordomo de la Cofradía de su pueblo natal, al igual que en 1709 y 1742 Baltasar de Murga. Ramírez Montes Guillermina, op. cit., p. 54. 
capacidad mucho mayor que otros emigrantes competidores a la hora de asentarse y, sobre todo, de integrarse en el nuevo espacio. Así, el análisis del frecuente éxito de los emigrantes vascos en tierras americanas se encuentra íntimamente vinculado con el fuerte carácter estructurante de los mecanismos empleados en el proceso. Unos instrumentos, que no se construyen en respuesta al hándicap que supone el proceso de emigración, sino que vienen a ser aquellos que, históricamente, se habían ido conformando como la base organizativa de la sociedad vasca del antiguo régimen.

El empleo de los mismos mecanismos que estructuraban la realidad social del lugar de origen, condiciona que el proceso migratorio de la población vasca del setecientos se encuentre con unas ventajas de salida frente a otros sectores e individuos que realizan el mismo trayecto. En una misma línea, el mantenimiento de una continua comunicación, con el lugar de origen, a través de la correspondencia y, primordialmente, por la llegada de familiares y parientes (sobre todo, sobrinos), una vez que se ha logrado un cierto nivel de asentamiento en el nuevo territorio, permiten conservar (no sin imperceptibles cambios a lo largo del tiempo) la esencia de la trama organizativa que les permite, a su vez, integrarse $y$ desarrollarse con éxito en el nuevo territorio.

Por otro lado la tradicional tendencia asociativa que se reproduce en todas las áreas en que se va instalando, por diferentes motivos (económicos, sociales, etc.), un sector de individuos oriundos de las provincias vascas les confiere un nuevo medio de estrechar las vinculaciones latentes en el grupo emigrante. Tanto asociaciones de carácter religioso (cofradías), que también gozaban de un gran peso en su tierra natal, hasta las más avanzadas por su carácter, teórico, ilustrado y racional (como la Real Sociedad Bascongada de Amigos del País), se instalan como centros de contacto, socialización y ayuda para aquellos que pretenden comenzar la carrera de Indias o integrarse en un territorio concreto.

En estas asociaciones, se unen los vínculos de carácter familiar con los provenientes de la amistad, del ejercicio de una misma actividad profesional, incluso los clientelares, junto a los meramente establecidos por medio del paisanaje o por una preocupación de índole intelectual o cultural. Así, se refuerzan los lazos de carácter familiar, clientelar o parental, adquiriendo un sentido más amplio y confiriendo, al grupo emigrante, un valor como colectivo, un "espíritu de cuerpo", que les permite actuar de manera más activa en favor de sus propios paisanos. 